\title{
Variações na composição e estrutura da vegetação permitem detectar agrupamentos florísticos em uma Floresta Subtropical Atlântica no Sul do Brasil?
}

\author{
João Paulo de Maçaneiro ${ }^{1 *}$ \\ Rafaela Cristina Seubert ${ }^{2}$ \\ Lauri Amândio Schorn ${ }^{2}$ \\ ${ }^{1}$ Universidade Federal do Paraná, Setor de Ciências Agrárias, Departamento de Ciências Florestais \\ Avenida Prefeito Lothário Meissner, 900, Jardim Botânico, CEP 80210-170, Curitiba - PR, Brasil \\ ${ }^{2}$ Universidade Regional de Blumenau, Centro de Ciências Tecnológicas \\ Departamento de Engenharia Florestal \\ Rua São Paulo, 3250, Itoupava Seca, CEP 89010-971, Blumenau - SC, Brasil \\ * Autor para correspondência \\ jpmacaneiro@gmail.com
}

Submetido em 29/03/2016

Aceito para publicação em 21/10/2016

\section{Resumo}

As variações da vegetação em função da posição topográfica têm despertado o interesse dos pesquisadores. Entretanto, poucos estudos verificaram as associações florísticas formadas pela posição topográfica de uma encosta. Neste trabalho, analisamos se as variações na vegetação permitem detectar agrupamentos florísticos em uma Floresta Pluvial Subtropical. A vegetação foi amostrada em 25 parcelas de $400 \mathrm{~m}^{2}$ distribuídas sistematicamente, onde foram medidos os indivíduos com DAP $\geq 5,0 \mathrm{~cm}$. Amostramos 1.727 indivíduos e 144 espécies. A ordenação NMDS segregou três grupos em função da posição topográfica da encosta (Monte Carlo, $P \geq 0,05$; ANOSIM, $P<0,001)$. Euterpe edulis e Sloanea guianensis se destacaram nos terços inferior e médio da encosta, enquanto Ocotea aciphylla e Alchornea triplinervia se destacaram no terço superior. Algumas espécies se mostraram indicadoras dos setores analisados, como é o caso de Actinostemon concolor e Alsophila setosa no terço inferior, Cyathea corcovadensis e Rudgea recurva no terço médio e Myrcia pulchra e Podocarpus sellowii no terço superior. Nossos resultados indicaram que as variações florísticas e estruturais observadas por Veloso e Klein (1959) e Klein $(1980 ; 1984)$ para o Vale do Itajaí em Santa Catarina apresentam validade estatística nos dias atuais, pois verificamos a formação de diferentes grupos de acordo com a posição topográfica da encosta.

Palavras-chave: Espécies indicadoras; Fitossociologia; Ordenação NMDS; Vale do Itajaí

\section{Abstract}

Do variations in the composition and structure of vegetation allow floristic groups to be detected in a subtropical moist forest in southern Brazil? Variations in vegetation based on topographic location have become an interest of researchers. However, few studies have verified floristic associations related to the topographic position of a slope. In this work, we analyzed if 
variations in vegetation allow floristic groups to be detected in a subtropical moist forest. The vegetation was sampled in 25 plots of $400 \mathrm{~m}^{2}$ distributed systematically, where individuals with a $\mathrm{DBH} \geq 5.0 \mathrm{~cm}$ were measured. We sampled 1,727 individuals and 144 species. The NMDS ordination segregated three groups based on the topographic position of the slope (Monte Carlo, $P \geq 0.05$; ANOSIM, $P<0.001)$. Euterpe edulis and Sloanea guianensis were notable in the lower and middle sections of the slope, whereas Ocotea aciphylla and Alchornea triplinervia were notable in the upper section. Some species were indicators of the analyzed sectors, such as Actinostemon concolor and Alsophila setosa in the lower section, Cyathea corcovadensis and Rudgea recurva in the middle section, and Myrcia pulchra and Podocarpus sellowii in the upper section. Our results indicate that the floristic and structural variations observed by Veloso and Klein (1959) and Klein $(1980 ; 1984)$ for Vale do Itajaí in Santa Catarina are statistically valid today, because we verified the formation of different groups according to the topographic position of the slope.

Key words: Indicator species; NMDS ordination; Phytosociology; Vale do Itajaí

\section{Introdução}

A composição e estrutura das espécies arbóreas em florestas neotropicais são determinadas por uma variedade de fatores que operam em diferentes escalas espaciais. Por exemplo, estudos realizados em escalas continentais têm demonstrado que a distribuição das espécies arbóreas está associada mais fortemente a fatores como precipitação total anual e duração da estação seca (GENTRY, 1988; PITMAN et al., 2002; ter STEEGE et al., 2003; 2006). Esses estudos verificaram que a riqueza de espécies arbóreas aumenta conforme o aumento da precipitação total anual, e diminui conforme o aumento da estação seca. Contudo, em uma escala local, a distribuição das espécies arbóreas pode ser determinada pela limitação de dispersão dos indivíduos e/ou em função de condições ambientais (PENÃ-CLAROS et a1., 2012). Em relação às condições ambientais, a topografia do terreno vem desempenhando um papel importante para descrever as variações na composição e estrutura da vegetação (POULSEN et al., 2006; RODRIGUES et al., 2007; GONÇALVES et al., 2011; SOUZA et al., 2012; 2013; MOESLUND et al., 2013; MAÇANEIRO et al., 2016), principalmente porque mudanças na topografia proporcionam alterações nos tipos de solos e em suas propriedades físicas e químicas, além de modificar o regime hídrico e estarem associadas aos processos de erosão das encostas (SENTHILKUMAR et al., 2009; MENDES et al., 2011; FERREIRA-JÚNIOR et al., 2012; MARANGON et al., 2013).
Em um gradiente topográfico, onde é possível distinguir os terços inferior, médio e superior da encosta, as áreas mais íngremes e com relevo acidentado tendem a dissipar material para as áreas mais baixas. Muitas vezes o escoamento superficial dos excessos hídricos promove a remoção das partículas mais leves do solo, que são depositadas na parte baixa da encosta, fazendo surgir um gradiente de textura mais fina encosta abaixo (RESENDE, 1988). Assim, dependendo do tipo de material de origem (rocha), o terço inferior das encostas pode ser caracterizado como áreas concentradoras e pode constituir solos profundos e com maior fertilidade (FERREIRA-JÚNIOR et al., 2012; MARANGON et al., 2013). Por outro lado, no terço médio e superior das encostas, cuja declividade do terreno geralmente é mais acentuada, há uma tendência desses ambientes apresentarem solos mais rasos e pobres em nutrientes (SCHAEFER et al., 2012; 2015).

Na região do Vale do Itajaí, em Santa Catarina, estudos históricos, como os de Veloso e Klein (1959) e Klein (1980; 1984), verificaram que ao subir uma encosta era possível observar nítida diferenciação na composição e fisionomia da vegetação. De acordo com os autores, essa constatação se tornava mais evidente quanto mais acentuada fosse a declividade do terreno. Assim, os autores definiram três zonas vegetacionais distintas, às quais correspondiam agrupamentos florísticos com características diferentes: i) terço inferior das encostas, caracterizado por relevo plano, solos profundos, úmidos e presença de vegetação bem desenvolvida e uniforme; ii) terço médio das encostas, 
caracterizado por relevo acidentado, solos variando de pouco profundos a rasos, e presença de vegetação exuberante com dossel descontínuo e heterogêneo e; iii) terço superior das encostas, caracterizado por relevo acidentado, solos rasos, às vezes rochosos e de rápida drenagem, o que condicionava a formação de uma vegetação aberta, homogênea e menos desenvolvida. Essas zonas vegetacionais, também conhecidas como unidades topográficas do terreno (FERREIRA-JÚNIOR et al., 2012), podem apresentar diferenças fisionômicas marcantes na vegetação, sobretudo na abundância e frequência de algumas espécies, que embora, possam ser encontradas em todos os ambientes, podem ser facilmente observadas com maior ou menor número de indivíduos em determinados ambientes (SOUZA et al., 2013; NARVAES et al., 2014).

Até o momento, nenhum trabalho foi realizado com o intuito de verificar de forma consistente os agrupamentos florísticos constituídos pelas zonas vegetacionais descritas por Veloso e Klein (1959) e Klein (1980; 1984). Neste trabalho, pretendemos contribuir com essa investigação e responder à seguinte pergunta: as variações na composição e estrutura do estrato arbóreo e arbustivo observadas por Veloso e Klein (1959) e Klein $(1980 ; 1984)$ para a região do Vale do Itajaí em Santa Catarina apresentam validade estatística? Como hipótese desta pesquisa, esperamos que sim, pois essa constatação foi verificada em estudos recentes realizados em outras fitofisionomias da Mata Atlântica - Floresta Estacional Semideciduifólia (FERREIRA-JÚNIOR et al., 2012; SOUZA et al., 2013) e Floresta Mista Lati-Aciculifoliada (NARVAES et al., 2014), que encontraram diferenças marcantes na composição, estrutura e fisionomia da vegetação em função da posição topográfica da encosta.

\section{Material e Métodos}

A área de estudo está inserida na bacia hidrográfica do rio Itajaí, em Brusque, Santa Catarina. Pertence à RPPN Chácara Edith, também conhecida pelos moradores da região como Fazenda Hoffmann, que possui área total de 415,8 ha, altitude que varia de $20 \mathrm{a}$ $300 \mathrm{~m}$ e está localizada entre $27^{\circ} 05^{\prime}$ e $27^{\circ} 06^{\prime} \mathrm{S}$ e $48^{\circ} 51^{\prime}$ e $48^{\circ} 54^{\prime} \mathrm{W}$. Esse local foi alvo do primeiro estudo fitossociológico de Santa Catarina, entre os anos 19491953 (VELOSO; KLEIN, 1957).

O clima do município de Brusque, segundo a classificação de Köppen, é do tipo Cfa - clima subtropical úmido sem estação seca e com verão quente (ALVARES et al., 2014). Sua temperatura média anual varia entre 19 e $20^{\circ} \mathrm{C}$, com médias mensais variando entre $15{ }^{\circ} \mathrm{C}$ no mês mais frio (julho) e $25{ }^{\circ} \mathrm{C}$ nos meses mais quentes (janeiro e fevereiro). A umidade relativa anual varia entre $84-86 \%$, com médias mensais entre $80 \%$ no mês mais quente (dezembro) e $88 \%$ nos meses mais frios (junho e julho) (PANDOLFO et al., 2002). Dados coletados pela Estação Brusque da Agência Nacional de Águas $\left(27^{\circ} 06^{\prime} 02,16^{\prime}\right.$ 'S, 48 55'04,08'W e $25 \mathrm{~m}$ de altitude), distante $2,8 \mathrm{~km}$ da área de estudo, registraram, no período de 1941 a 2013, precipitações totais anuais que variaram de 460 a $3.004 \mathrm{~mm}$, com média de $1.568 \mathrm{~mm}$.

A geologia da região é formada pelo Complexo Metamórfico Brusque, composto pela Formação Botuverá, pelo Granodiorito Valsungana e pelo Granito Guabiruba (SCHULZ-JÚNIOR; ALBUQUERQUE, 1969; SANTA CATARINA, 1986). Essa formação é constituída por uma associação metavulcano-sedimentar composta por filitos e xistos micáceos intercalados com semipelitos, quartzitos, rochas cálci-silicáticas, mármores, xistos magnesianos e metavulcânicas básicas (PHILIPP et al., 2004). Predomina, na região de estudo, uma associação entre dois tipos de solos: em relevos ondulados o Cambissolo Háplico Tb A moderado de textura argilosa e, em relevo forte ondulado e montanhoso, o Neossolo Litólico Distrófico A moderado de textura argilosa (EMBRAPA, 2004).

A vegetação predominante na área de estudo é constituída pela Floresta Latifoliada Subtropical Pluvial Perenifólia de Morrarias Baixas (OLIVEIRA-FILHO, 2015), daqui em diante referida como Floresta Pluvial Subtropical, estando inserida no domínio da Mata Atlântica. Em 1923, o antigo proprietário da reserva iniciou a exploração madeireira na área de estudo, que ocorreu até 1930. Essa exploração teve como foco a canela-preta (Ocotea catharinensis Mez) e outras espécies de interesse econômico. A reserva foi explorada durante o início de 1900, mas a vegetação encontra- 
se aproximadamente 80 anos sem ação antrópica (MAÇANEIRO et al., 2015b).

Para a coleta dos dados, utilizamos parcelas dispostas em transecções (SOARES et al., 2012), com o objetivo de representar a maior variação da vegetação possível ao longo da encosta analisada. Dispusemos as parcelas em cinco transecções, todas iniciando no terço inferior da encosta, em cotas de $50 \mathrm{~m}$ s.n.m. e terminando no terço superior da encosta, em cotas de 162 m s.n.m. No total distribuímos, de forma sistemática, 25 parcelas de $20 \times 20 \mathrm{~m}\left(400 \mathrm{~m}^{2}\right)$, totalizando $10.000 \mathrm{~m}^{2}$ de área amostral. Distanciamos essas parcelas aproximadamente $50 \mathrm{~m}$ entre si e $25 \mathrm{~m}$ entre as transecções. Em cada parcela, amostramos os indivíduos arbóreos e arbustivos vivos, incluindo palmeiras e fetos arborescentes, com $\mathrm{DAP} \geq 5,0 \mathrm{~cm}$.

Identificamos o material botânico coletado por comparação com fotografias digitais nos sítios da Flora Digital (FLORA DIGITAL, 2016) e do Herbário Virtual (REFLORA, 2016), com exsicatas depositadas no Herbário Dr. Roberto Miguel Klein, da Universidade Regional de Blumenau (FURB) e, também, mediante consulta à literatura taxonômica e aos especialistas da FURB. Enviamos duplicatas de espécies das famílias Lauraceae e Myrtaceae aos especialistas.

Aplicamos o Escalonamento Multidimensional Não Métrico (NMDS) no PC-ORD 6.0 (McCUNE; MEFFORD, 2011), com o objetivo de investigar como as parcelas se ordenavam no espaço multidimensional da composição e abundância das espécies. Utilizamos a distância de Sørensen para a matriz de composição de espécies e a distância de Bray-Curtis para a matriz de abundância de indivíduos das espécies. Para verificar a consistência do NMDS, calculamos uma medida de stress, que indica a proporção da variância das disparidades não explicadas pelo modelo NMDS (HAIR et al., 2009). Testamos a significância estatística do stress por meio do teste de Monte Carlo, com 250 permutações. Confirmamos a estabilidade do stress na porção final das iterações, conforme sugerido por McCune e Grace (2002) para uma análise confiável. Verificamos a significância estatística dos agrupamentos florísticos formados pelo NMDS por meio da ANOSIM (CLARKE, 1993).
Com base nos agrupamentos florísticos formados pelo NMDS (Figura 1), analisamos a estrutura da vegetação por meio dos parâmetros fitossociológicos de Mueller-Dombois e Ellenberg (2002), ou seja, densidade, dominância e frequências absolutas e relativas e o valor de importância para cada espécie. Nessa análise, utilizamos as subparcelas de $10 \times 10$ m para aumentar a precisão das estimativas dos parâmetros fitossociológicos, ficando assim distribuídas: terço inferior: 44 subparcelas; terço médio: 40 e terço superior: 16, respectivamente. Em seguida, verificamos as espécies diferenciais de cada agrupamento florístico por meio da Análise de Espécies Indicadoras (ISA), obtendo os valores indicadores para cada espécie pelo método de Tichý e Chytrý (2006) no PC-ORD 6.0 (McCUNE; MEFFORD, 2011). Testamos a significância estatística de cada valor indicador por meio do teste de Monte Carlo, com 9999 permutações.

Com o intuito de analisar a preferência que as espécies possuem em função de determinado tipo de solo, adotamos a classificação de Veloso e Klein (1957; 1959) e Klein (1979; 1980). Esses autores classificaram as espécies arbóreas e arbustivas, incluindo palmeiras e fetos arborescentes, da região do Vale do Itajaí-SC em diferentes categorias ecológicas, as quais são fundamentadas na preferência que as espécies possuem por solos mais ou menos úmidos e em função da posição topográfica de uma encosta: i) higrófita (Hig) - espécie que prefere como o seu ótimo ambientes com solo úmido; ii) xerófita (Xer) - espécie que prefere como o seu ótimo ambientes com solo seco; iii) indiferente (Ind) - espécie que pode ocorrer em todos os ambientes sem apresentar afinidades pronunciadas por determinado tipo de solo. Devido à escassez de informações ecológicas disponíveis para algumas espécies registradas no presente estudo, adotamos a nomenclatura "espécie com deficiência de dados para classificação" para as espécies que não constavam na base de dados de Veloso e Klein $(1957 ; 1959)$ e Klein $(1979 ; 1980)$ no Vale do Itajaí-SC.

\section{Resultados}

$\mathrm{Na}$ ordenação produzida pelo Escalonamento Multidimensional Não Métrico (NMDS), a maior diferenciação esteve presente entre as parcelas inseridas 
nos terços inferior e superior da encosta, onde constatamos as menores afinidades entre a vegetação (Figura 1). Verificamos a formação de três grupos florísticos, os quais se caracterizam pela posição da encosta. $\mathrm{O}$ grupo I foi formado por parcelas inseridas no terço médio da encosta. O grupo II foi formado por parcelas inseridas no terço inferior e o grupo III pelas parcelas inseridas no terço superior. Os dois primeiros eixos de ordenação das matrizes de composição e abundância segregaram as parcelas dos terços inferior, médio e superior da encosta, e produziram $83,9 \%$ e $91,5 \%$, respectivamente, da correlação entre as distâncias de ordenação e o espaço n-dimensional original. O stress médio obtido para os dados reais $($ composição $=14,8 \%$; abundância $=11,2 \%)$ e aleatorizados $($ composição $=27,9 \%$; abundância $=$ $21,1 \%$ ) dos dois primeiros eixos de ordenação do NMDS se mantiveram estáveis na porção final das iterações, e apresentaram significância estatística (Monte Carlo, $P \leq 0,05)$. Além disso, os três grupos florísticos formados pelo NMDS apresentaram diferenças significativas entre si no que diz respeito à composição e abundância de espécies (ANOSIM, $P<0,001$ ).

Nos três agrupamentos florísticos, amostramos 1.727 indivíduos pertencentes a 144 espécies (Tabela 1). No terço inferior da encosta (grupo II), as principais espécies que caracterizaram a estrutura

FIGURA 1: Diagramas de ordenação das parcelas produzidos pelo Escalonamento Multidimensional Não Métrico (NMDS), com base na composição (a) e abundância (b) de espécies em 25 parcelas de uma Floresta Pluvial Subtropical no Sul do Brasil.

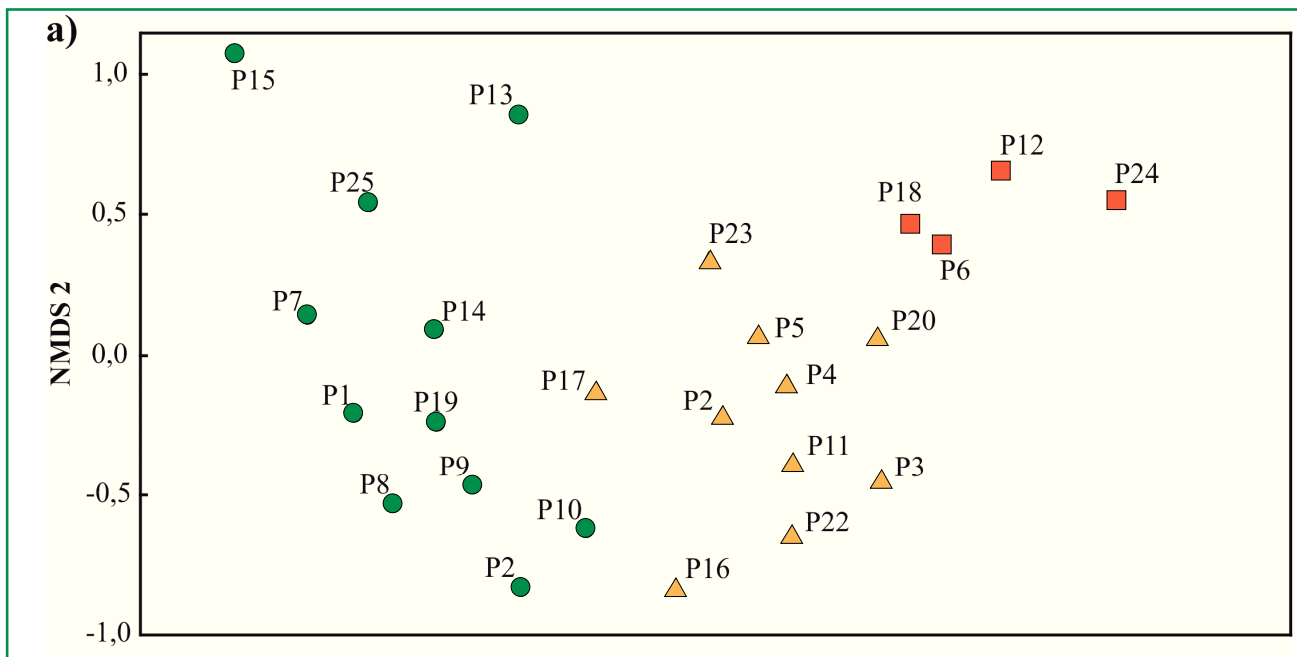

\section{b)}

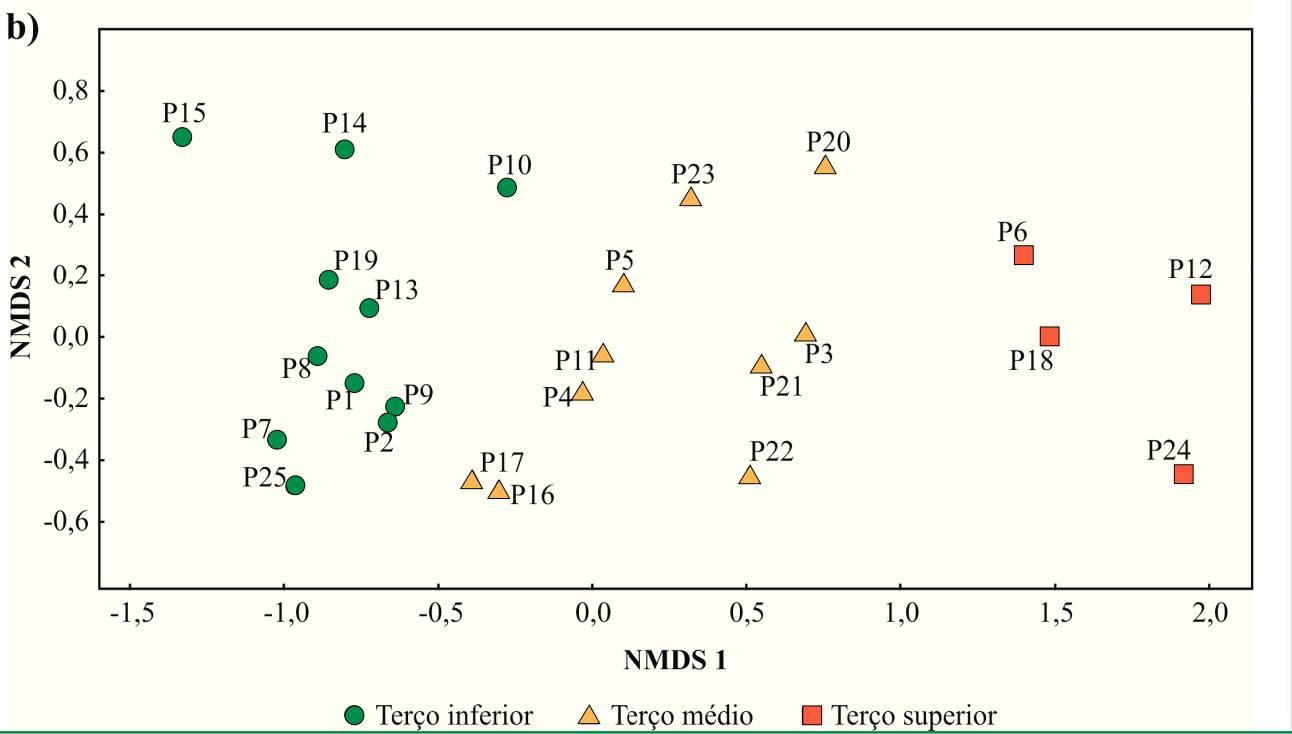


da floresta foram Euterpe edulis, Sloanea guianensis, Cyathea delgadii, Ocotea catharinensis e Alsophila setosa $(\mathrm{VI}=107,7 \%)$, sendo que a primeira delas foi a mais importante, principalmente pelos seus elevados valores de densidade e frequência (Tabela 2). Detectamos também sete espécies indicadoras no terço inferior da encosta
(Tabela 3) e as espécies que apresentaram o maior índice de valor indicador foram Actinostemon concolor, Alsophila setosa, Cyathea delgadii e Pterocarpus rohrii (IVI $>60 \%$ ). O grupo de espécies que predominou no grupo II foram as higrófitas $(45,6 \%)$, seguida das indiferentes $(31,1 \%)$ e xerófitas $(13,6 \%)$.

TABELA 1: Famílias e espécies registradas com seus respectivos números de indivíduos medidos, em uma Floresta Pluvial Subtropical no Sul do Brasil. Solo = preferência por determinado tipo de solo: Hig = higrófita, Ind = indiferente, Xer = xerófita; * = espécie com deficiência de dados para classificação.

\begin{tabular}{|c|c|c|c|c|c|}
\hline \multirow{2}{*}{ Família } & \multirow{2}{*}{ Espécie } & \multirow{2}{*}{ Solo } & \multicolumn{3}{|c|}{ Posição da Encosta } \\
\hline & & & Inferior & Médio & Superior \\
\hline Anacardiaceae & Tapirira guianensis Aubl. & Xer & 3 & 16 & 17 \\
\hline \multirow[t]{3}{*}{ Annonaceae } & Duguetia lanceolata A.St.-Hil. & Ind & 2 & 7 & 3 \\
\hline & Guatteria australis A.St.-Hil. & Xer & & 10 & 10 \\
\hline & Xylopia brasiliensis Spreng. & Xer & & 7 & 11 \\
\hline \multirow{3}{*}{ Apocynaceae } & Aspidosperma australe Müll.Arg. & Ind & 6 & 3 & \\
\hline & Aspidosperma tomentosum Mart. & Ind & 2 & 1 & \\
\hline & Tabernaemontana catharinensis A.DC. & Hig & 1 & & \\
\hline \multirow[t]{2}{*}{ Aquifoliaceae } & Ilex paraguariensis A.St.-Hil. & Hig & & 1 & \\
\hline & Ilex theezans Mart. ex Reissek & Xer & & 5 & 3 \\
\hline \multirow[t]{2}{*}{ Araliaceae } & Schefflera angustissima (Marchal) Frodin & Xer & & 2 & \\
\hline & Schefflera morototoni (Aubl.) Maguire et al. & Xer & 1 & 5 & \\
\hline Arecaceae & Euterpe edulis Mart. & Ind & 273 & 164 & 5 \\
\hline \multirow[t]{2}{*}{ Bignoniaceae } & Cybistax antisyphilitica (Mart.) Mart. & Hig & 1 & & \\
\hline & Jacaranda micrantha Cham. & Hig & 1 & & \\
\hline Burseraceae & Protium kleinii Cuatrec. & Ind & & 5 & \\
\hline Celastraceae & Maytenus gonoclada Mart. & Hig & 6 & 6 & 1 \\
\hline Chrysobalanaceae & Hirtella hebeclada Moric. ex DC. & Xer & 4 & 7 & \\
\hline Clethraceae & Clethra scabra Pers. & Xer & & & 2 \\
\hline \multirow[t]{2}{*}{ Clusiaceae } & Clusia criuva Cambess. & Ind & & & 2 \\
\hline & Garcinia gardneriana (Planch. \& Triana) Zappi & Ind & 24 & 40 & 2 \\
\hline Cunoniaceae & Weinmannia paulliniifolia Pohl ex Ser. & Ind & & & 1 \\
\hline \multirow[t]{3}{*}{ Cyatheaceae } & Alsophila setosa Kaulf. & Hig & 37 & & \\
\hline & Cyathea corcovadensis (Raddi) Domin & Xer & 19 & 47 & \\
\hline & Cyathea delgadii Sternb. & Hig & 45 & 6 & 2 \\
\hline Elaeocarpaceae & Sloanea guianensis (Aubl.) Benth. & Ind & 42 & 56 & 9 \\
\hline \multirow[t]{3}{*}{ Euphorbiaceae } & Actinostemon concolor (Spreng.) Müll.Arg. & Hig & 17 & & \\
\hline & Alchornea triplinervia (Spreng.) Müll.Arg. & Ind & 7 & 2 & 20 \\
\hline & Aparisthmium cordatum (A.Juss.) Baill. & Xer & 7 & 20 & 27 \\
\hline \multirow[t]{10}{*}{ Fabaceae } & Abarema langsdorffii (Benth.) Barneby \& J.W.Grimes & Ind & & 4 & \\
\hline & Andira fraxinifolia Benth. & Hig & 3 & 1 & 4 \\
\hline & Copaifera trapezifolia Hayne & Ind & 8 & 5 & \\
\hline & Dalbergia brasiliensis Vogel & $*$ & & 1 & \\
\hline & Inga sellowiana Benth. & Hig & 3 & 1 & \\
\hline & Machaerium hirtum (Vell.) Stellfeld & $*$ & 1 & & \\
\hline & Myrocarpus frondosus Allemão & Hig & 1 & & \\
\hline & Ormosia arborea (Vell.) Harms & Xer & & 1 & \\
\hline & Pterocarpus rohrii Vahl & Hig & 7 & & \\
\hline & Zollernia ilicifolia (Brongn.) Vogel & Hig & 1 & & \\
\hline
\end{tabular}




\begin{tabular}{|c|c|c|c|c|c|}
\hline Humiriaceae & Vantanea compacta (Schnizl.) Cuatrec. & Xer & & 18 & 8 \\
\hline \multirow[t]{19}{*}{ Lauraceae } & Aiouea saligna Meisn. & Ind & & 1 & \\
\hline & Aniba firmula (Nees \& Mart.) Mez & Hig & 4 & 2 & \\
\hline & Cryptocarya mandioccana Meisn. & Ind & 12 & 12 & \\
\hline & Cryptocarya sp. & - & 1 & 3 & \\
\hline & Nectandra oppositifolia Nees & Ind & 2 & 1 & \\
\hline & Ocotea aciphylla (Nees \& Mart.) Mez & Xer & 1 & 36 & 28 \\
\hline & Ocotea bicolor Vattimo-Gil & $*$ & & 1 & 2 \\
\hline & Ocotea catharinensis Mez & Ind & 13 & 7 & \\
\hline & Ocotea dispersa (Nees \& Mart.) Mez & Ind & & 2 & \\
\hline & Ocotea elegans $\mathrm{Mez}$ & Ind & 6 & 8 & \\
\hline & Ocotea lanata (Nees \& Mart.) Mez & $*$ & & & 1 \\
\hline & Ocotea mandioccana A.Quinet & * & 1 & & \\
\hline & Ocotea nectandrifolia $\mathrm{Mez}$ & $*$ & 2 & 1 & \\
\hline & Ocotea odorifera (Vell.) Rohwer & Xer & 1 & 6 & 7 \\
\hline & Ocotea pulchra Vattimo-Gil & Xer & & 3 & 9 \\
\hline & Ocotea silvestris Vattimo-Gil & $*$ & & 1 & \\
\hline & Ocotea sp. & - & & 2 & \\
\hline & Persea major (Meisn.) L.E.Kopp & $*$ & & & 1 \\
\hline & Persea venosa Nees \& Mart. & $*$ & 1 & & \\
\hline Magnoliaceae & Magnolia ovata (A.St.-Hil.) Spreng. & Hig & 3 & & \\
\hline Malpighiaceae & Byrsonima ligustrifolia A.Juss. & Xer & 5 & 16 & 5 \\
\hline Malvaceae & Pseudobombax grandiflorum (Cav.) A.Robyns & Hig & 4 & & \\
\hline \multirow[t]{7}{*}{ Melastomataceae } & Henriettella glabra (Vell.) Cogn. & $*$ & 4 & 1 & \\
\hline & Miconia budlejoides Triana & Xer & & 3 & \\
\hline & Miconia cabucu Hoehne & Xer & & & 2 \\
\hline & Miconia cubatanensis Hoehne & Xer & & & 1 \\
\hline & Miconia pusilliflora (DC.) Naudin & $*$ & & & 1 \\
\hline & Mouriri chamissoana Cogn. & Ind & 1 & & \\
\hline & Tibouchina pulchra Cogn. & $*$ & 1 & & \\
\hline \multirow[t]{3}{*}{ Meliaceae } & Cabralea canjerana (Vell.) Mart. & Ind & 2 & 12 & 6 \\
\hline & Cedrela fissilis Vell. & Hig & 3 & & \\
\hline & Trichilia casaretti C.DC. & Hig & 2 & 1 & \\
\hline \multirow[t]{5}{*}{ Monimiaceae } & Mollinedia clavigera Tul. & Xer & & 9 & 3 \\
\hline & Mollinedia schottiana (Spreng.) Perkins & Ind & 3 & 2 & \\
\hline & Mollinedia triflora (Spreng.) Tul. & Ind & 2 & 3 & \\
\hline & Mollinedia uleana Perkins & Ind & & 1 & \\
\hline & Mollinedia sp. & $*$ & & 1 & 1 \\
\hline \multirow[t]{4}{*}{ Moraceae } & Brosimum glaziovii Taub. & Hig & & 1 & \\
\hline & Brosimum lactescens (S.Moore) C.C.Berg & Hig & 4 & 5 & \\
\hline & Ficus gomelleira Kunth & $*$ & & 2 & \\
\hline & Sorocea bonplandii (Baill.) W.C.Burger et al. & Hig & 4 & & \\
\hline Myristicaceae & Virola bicuhyba (Schott ex Spreng.) Warb. & Ind & 5 & 7 & \\
\hline \multirow[t]{10}{*}{ Myrtaceae } & Calyptranthes grandifolia O.Berg & Hig & & & 3 \\
\hline & Calyptranthes lucida Mart. ex DC. & Hig & 2 & 1 & \\
\hline & Calyptranthes strigipes O.Berg & Ind & 13 & 7 & \\
\hline & Eugenia beaurepaireana (Kiaersk.) D.Legrand & Hig & 2 & 7 & \\
\hline & Eugenia brasiliensis Lam. & Hig & 3 & & \\
\hline & Eugenia brevistyla D.Legrand & Hig & & 2 & \\
\hline & Eugenia cerasiflora Miq. & Hig & 2 & & \\
\hline & Eugenia handroana D.Legrand & Ind & 5 & 7 & \\
\hline & Eugenia kleinii D.Legrand & Ind & 1 & 1 & \\
\hline & Eugenia multicostata D.Legrand & Hig & 3 & & \\
\hline
\end{tabular}




\begin{tabular}{|c|c|c|c|c|c|}
\hline & Eugenia stigmatosa DC. & Hig & 2 & & \\
\hline & Eugenia verticillata (Vell.) Angely & Hig & 2 & & \\
\hline & Marlierea excoriata Mart. & Hig & 3 & & \\
\hline & Marlierea silvatica (O.Berg) Kiaersk. & Ind & 3 & & \\
\hline & Marlierea tomentosa Cambess. & Hig & 3 & & \\
\hline & Myrcia aethusa (O.Berg) N.Silveira & Ind & 2 & 2 & \\
\hline & Myrcia brasiliensis Kiaersk. & Xer & 6 & 1 & 1 \\
\hline & Myrcia dichrophylla D.Legrand & Hig & & 3 & 6 \\
\hline & Myrcia glabra (O.Berg) D.Legrand & Hig & 1 & 1 & \\
\hline & Myrcia guianensis (Aubl.) DC. & Ind & & 2 & \\
\hline & Myrcia hebepetala DC. & Ind & & & 8 \\
\hline & Myrcia pubipetala Miq. & Ind & & & 1 \\
\hline & Myrcia pulchra (O.Berg) Kiaersk. & $*$ & 4 & & \\
\hline & Myrcia spectabilis DC. & Ind & & & 8 \\
\hline & Myrcia tijucensis Kiaersk. & Ind & 2 & & \\
\hline & Myrciaria floribunda (H.West ex Willd.) O.Berg & Hig & 1 & 7 & \\
\hline & Myrciaria plinioides D.Legrand & Hig & & 3 & \\
\hline & Myrciaria tenella (DC.) O.Berg & Hig & 3 & & \\
\hline & Neomitranthes glomerata (D.Legrand) D.Legrand & Hig & & 1 & \\
\hline & Pimenta pseudocaryophyllus (Gomes) Landrum & Hig & 4 & 1 & \\
\hline & Plinia pseudodichasiantha (Kiaersk.) G.M.Barroso ex Sobral & $*$ & & & 1 \\
\hline & Não identificada 1 & - & & 1 & \\
\hline & Não identificada 2 & - & 1 & & \\
\hline & Não identificada 3 & - & & & 1 \\
\hline Nyctaginaceae & Guapira opposita (Vell.) Reitz & Hig & 1 & 3 & \\
\hline & Pisonia ambigua Heimerl & Hig & 7 & 1 & \\
\hline Ochnaceae & Ouratea parviflora (A.DC.) Baill. & Ind & 1 & & \\
\hline Olacaceae & Heisteria silvianii Schwacke & Ind & 2 & & \\
\hline Peraceae & Pera glabrata (Schott) Poepp. ex Baill. & Ind & 3 & 9 & \\
\hline Phyllanthaceae & Hyeronima alchorneoides Allemão & Hig & 1 & 2 & \\
\hline & Richeria grandis Vahl & Hig & & 1 & \\
\hline Podocarpaceae & Podocarpus sellowii Klotzsch ex Endl. & Xer & & 1 & \\
\hline Polygonaceae & Coccoloba warmingii Meisn. & Xer & & & 6 \\
\hline Primulaceae & Cybianthus brasiliensis (Mez) G.Agostini & Xer & 1 & 1 & \\
\hline & $\begin{array}{l}\text { Myrsine hermogenesii (Jung-Mend \& Bernacci) } \\
\text { M.F.Freitas\&Kin.Gouv }\end{array}$ & Xer & & 1 & 2 \\
\hline Quiinaceae & Quiina glaziovii Engl. & Hig & 3 & 1 & \\
\hline Rubiaceae & Amaioua guianensis Aubl. & Xer & 5 & 15 & 17 \\
\hline & Bathysa australis (A.St.-Hil.) K.Schum. & Hig & 4 & 1 & \\
\hline & Cordiera concolor (Cham.) Kuntze & Hig & 2 & 2 & \\
\hline & Faramea montevidensis (Cham. \& Schltdl.) DC. & Ind & 10 & 2 & \\
\hline & Psychotria carthagenensis Jacq. & Ind & 1 & 4 & \\
\hline & Psychotria nemorosa Gardner & Hig & 1 & & \\
\hline & Rudgea jasminoides (Cham.) Müll.Arg. & Hig & 3 & & \\
\hline & Rudgea recurva Müll.Arg. & Hig & 7 & 27 & \\
\hline Rutaceae & Esenbeckia grandiflora Mart. & Xer & 2 & 3 & \\
\hline Sabiaceae & Meliosma sellowii Urb. & Hig & 1 & & \\
\hline Salicaceae & Casearia obliqua Spreng. & Hig & 1 & & \\
\hline Sapindaceae & Matayba intermedia Radlk. & Ind & 4 & 3 & \\
\hline Sapotaceae & Chrysophyllum viride Mart. \& Eichler & Hig & 1 & & \\
\hline & Pouteria venosa (Mart.) Baehni & Hig & 4 & & \\
\hline Theaceae & Laplacea fructicosa (Schrad.) Kobuski & $*$ & & 1 & \\
\hline Urticaceae & Cecropia glaziovii Snethl. & Ind & 5 & & \\
\hline & Pourouma guianensis Aubl. & $*$ & & 5 & \\
\hline
\end{tabular}


No terço médio da encosta (grupo I), as principais espécies que caracterizaram a estrutura da floresta foram Euterpe edulis, Sloanea guianensis, Ocotea aciphylla, Vantanea compacta, Tapirira guianensis e Cyathea corcovadensis $(\mathrm{VI}=121,4 \%)$. Semelhante ao encontrado no terço inferior da encosta, Euterpe edulis e Sloanea guianensis também foram as espécies mais importantes no terço médio da encosta (Tabela 2), indicando sua preferência por esses dois tipos de habitats. As espécies indicadoras desse agrupamento florístico foram Cyathea corcovadensis, Heisteria silvianii, Rudgea recurva, Abarema langsdorffii e Protium kleinii (IVI > 50\%) (Tabela 3). O grupo de espécies que predominou nesse agrupamento foram as indiferentes $(31,8 \%)$, seguida das higrófitas $(29,4 \%)$ e xerófitas $(25,9 \%)$.
No terço superior da encosta (grupo III), a estrutura da vegetação se caracterizou por Ocotea aciphylla, Alchornea triplinervia, Tapirira guianensis, Aparisthmium cordatum, Amaioua guianensis e Vantanea compacta (VI = 138,9\%) (Tabela 2). Detectamos 13 espécies indicadoras no terço superior da encosta (Tabela 3) e duas delas (Myrcia pulchra e Podocarpus sellowii) apresentaram valor indicador máximo (IVI $=100 \%$ ), ou seja, ocorreram apenas nas parcelas desse agrupamento. Outras espécies que também apresentaram valores indicadores elevados foram Myrcia guianensis, Ocotea pulchra, Xylopia brasiliensis e Alchornea triplinervia (IVI $>65 \%$ ). O grupo de espécies que predominou nesse agrupamento foram as xerófitas $(46,3 \%)$, seguida das indiferentes $(26,8 \%)$ e higrófitas $(12,2 \%)$.

TABELA 2: Parâmetros fitossociológicos calculados para as dez espécies com maior valor de importância em três posições da encosta de uma Floresta Pluvial Subtropical no Sul do Brasil. n = número de indivíduos amostrados; $\mathrm{DA}=$ densidade absoluta $\left(\right.$ ind.ha $\left.^{-1}\right) ; \mathrm{DR}=$ densidade relativa $(\%) ; \mathrm{FA}=$ frequência absoluta $(\%) ; \mathrm{FR}=$ frequência relativa $(\%) ;$ DoA $=$ dominância absoluta $\left(\mathrm{m}^{2} \cdot \mathrm{ha}^{-1}\right) ; \mathrm{DoR}=$ dominância relativa $(\%)$ e; VI = valor de importância (\%).

\begin{tabular}{|c|c|c|c|c|c|c|c|c|}
\hline Espécie & $\mathrm{n}$ & DA & DR & FA & FR & DoA & DoR & VI \\
\hline \multicolumn{9}{|c|}{ Terço inferior (44 parcelas, $4.400 \mathrm{~m}^{2}$ ) } \\
\hline Euterpe edulis & 273 & 682,5 & 36,1 & 100,0 & 9,6 & 4,7 & 11,0 & 56,7 \\
\hline Sloanea guianensis & 42 & 105,0 & 5,6 & 57,5 & 5,5 & 2,6 & 6,1 & 17,2 \\
\hline Cyathea delgadii & 45 & 112,5 & 5,9 & 65,0 & 6,2 & 0,5 & 1,2 & 13,4 \\
\hline Ocotea catharinensis & 13 & 32,5 & 1,7 & 27,5 & 2,6 & 2,5 & 5,9 & 10,2 \\
\hline Alsophila setosa & 37 & 92,5 & 4,9 & 45,0 & 4,3 & 0,4 & 1,0 & 10,2 \\
\hline Pseudobombax grandiflorum & 4 & 10,0 & 0,5 & 10,0 & 1,0 & 3,0 & 6,9 & 8,4 \\
\hline Alchornea triplinervia & 7 & 17,5 & 0,9 & 15,0 & 1,4 & 2,4 & 5,6 & 8,0 \\
\hline Garcinia gardneriana & 24 & 60,0 & 3,8 & 37,5 & 3,6 & 0,4 & 0,8 & 7,6 \\
\hline Hyeronima alchorneoides & 9 & 22,5 & 1,2 & 22,5 & 2,2 & 1,8 & 4,1 & 7,5 \\
\hline Aspidosperma australe & 6 & 15,0 & 0,8 & 15,0 & 1,4 & 2,2 & 5,1 & 7,4 \\
\hline Outras espécies & 296 & 740,0 & 39,2 & - & 62,2 & 22,4 & 52,2 & 153,5 \\
\hline Total & 756 & $1.890,0$ & 100,0 & - & 100,0 & 42,9 & 100,0 & 300,0 \\
\hline \multicolumn{9}{|c|}{ Terço médio (40 parcelas, $\left.4.000 \mathrm{~m}^{2}\right)$} \\
\hline Euterpe edulis & 164 & 372,7 & 22,7 & 90,9 & 8,5 & 2,0 & 5,1 & 36,3 \\
\hline Sloanea guianensis & 56 & 127,3 & 7,7 & 70,5 & 6,6 & 4,8 & 12,5 & 26,9 \\
\hline Ocotea aciphylla & 36 & 81,8 & 5,0 & 40,9 & 3,8 & 3,8 & 9,9 & 18,7 \\
\hline Vantanea compacta & 18 & 40,9 & 2,5 & 29,5 & 2,8 & 3,3 & 8,7 & 13,9 \\
\hline Tapirira guianensis & 16 & 36,4 & 2,2 & 25,0 & 2,3 & 3,2 & 8,3 & 12,9 \\
\hline Cyathea corcovadensis & 47 & 106,8 & 6,5 & 50,0 & 4,7 & 0,6 & 1,5 & 12,7 \\
\hline Garcinia gardneriana & 40 & 90,9 & 5,5 & 52,3 & 4,9 & 0,4 & 1,1 & 11,6 \\
\hline Cabralea canjerana & 12 & 27,3 & 1,7 & 25,0 & 2,3 & 2,1 & 5,4 & 9,4 \\
\hline Rudgea recurva & 27 & 61,4 & 3,7 & 43,2 & 4,1 & 0,2 & 0,6 & 8,4 \\
\hline Cryptocarya mandioccana & 12 & 27,3 & 1,7 & 27,3 & 2,6 & 1,3 & 3,4 & 7,6 \\
\hline Outras espécies & 295 & 670,5 & 40,8 & - & 57,4 & 16,8 & 43,5 & 141,7 \\
\hline Total & 723 & $1.643,2$ & 100,0 & - & 100,0 & 38,6 & 100,0 & 300,0 \\
\hline
\end{tabular}




\begin{tabular}{|c|c|c|c|c|c|c|c|c|}
\hline \multicolumn{9}{|c|}{ Terço superior (16 parcelas, $1.600 \mathrm{~m}^{2}$ ) } \\
\hline Ocotea aciphylla & 28 & 175,0 & 11,3 & 81,3 & 7,8 & 4,0 & 10,1 & 29,2 \\
\hline Alchornea triplinervia & 20 & 125,0 & 8,1 & 68,8 & 6,6 & 5,1 & 13,0 & 27,7 \\
\hline Tapirira guianensis & 17 & 106,3 & 6,9 & 56,3 & 5,4 & 5,6 & 14,3 & 26,6 \\
\hline Aparisthmium cordatum & 27 & 168,8 & 10,9 & 75,0 & 7,2 & 1,2 & 3,1 & 21,2 \\
\hline Amaioua guianensis & 17 & 106,3 & 6,9 & 68,8 & 6,6 & 1,6 & 4,0 & 17,4 \\
\hline Vantanea compacta & 8 & 50,0 & 3,2 & 31,3 & 3,0 & 4,1 & 10,6 & 16,8 \\
\hline Xylopia brasiliensis & 11 & 68,8 & 4,4 & 56,3 & 5,4 & 2,3 & 5,9 & 15,7 \\
\hline Myrcia pulchra & 8 & 50,0 & 3,2 & 43,8 & 4,2 & 1,8 & 4,6 & 12,0 \\
\hline Sloanea guianensis & 9 & 56,3 & 3,6 & 31,3 & 3,0 & 2,0 & 5,0 & 11,6 \\
\hline Guatteria australis & 10 & 62,5 & 4,0 & 43,8 & 4,2 & 1,0 & 2,5 & 10,8 \\
\hline Outras espécies & 93 & 581,3 & 37,5 & - & 46,7 & 10,5 & 26,8 & 111,0 \\
\hline Total & 248 & $1.550,0$ & 100,0 & - & 100,0 & 39,3 & 100,0 & 300,0 \\
\hline
\end{tabular}

TABELA 3: Lista com as espécies indicadoras por posição da encosta em uma Floresta Pluvial Subtropical no Sul do Brasil. IVI $=$ índice de valor indicador (significativo para $P<0,05$ ).

\begin{tabular}{lcc}
\hline Posição da encosta/espécies & IVI (\%) & $\boldsymbol{P}$ \\
\hline Terço inferior & & $<0,01$ \\
Actinostemon concolor & 92,6 & $<0,01$ \\
Alsophila setosa & 92,6 & 0,001 \\
Cyathea delgadii & 69,2 & 0,010 \\
Guapira opposita & 58,5 & 0,017 \\
Hyeronima alchorneoides & 57,2 & 0,021 \\
Cecropia glaziovii & 55,5 & 0,022 \\
Pterocarpus rohrii & 63,2 & 0,022 \\
Pseudobombax grandiflorum & 55,5 & $<0,01$ \\
\hline Terço médio & & 0,029 \\
Cyathea corcovadensis & 55,5 & 0,043 \\
Heisteria silvianii & 50,4 & 0,049 \\
Rudgea recurva & 57,8 & 0,049 \\
Abarema langsdorffii & 52,5 & \\
Protium kleinii & 52,5 & $<0,01$ \\
Terço superior & & $<0,01$ \\
Myrcia pulchra & 100,0 & $<0,01$ \\
Podocarpus sellowii & 100,0 & $<0,01$ \\
Myrcia guianensis & 81,6 & 0,017 \\
Ocotea pulchra & 81,6 & 0,018 \\
Xylopia brasiliensis & 67,4 & 0,020 \\
Alchornea triplinervia & 67,4 & 0,022 \\
Miconia cabucu & 63,2 & 0,025 \\
Myrsine hermogenesii & 63,2 & 0,028 \\
Clusia criuva & 63,2 & 0,028 \\
Vantanea compacta & 63,2 & 0,034 \\
Guatteria australis & 63,2 & 0,034 \\
Myrcia brasiliensis & 60,2 & 60,2 \\
Andira fraxinifolia & & \\
\hline
\end{tabular}




\section{Discussão}

Detectamos variações florísticas e estruturais consistentes entre os agrupamentos florísticos formados em função da posição topográfica da encosta. Nossos resultados também se mostraram consistentes com os estudos realizados por Veloso e Klein (1959) e Klein $(1980 ; 1984)$ no Vale do Itajaí-SC, indicando que ao longo de uma encosta é possível detectar agrupamentos florísticos. Ferreira-Júnior et al. (2012) e Narvaes et al. (2014) verificaram três compartimentos em um gradiente pedológico-geomorfológico em remanescentes de Floresta Estacional Semideciduifólia e Floresta Mista Lati-aciculifoliada, respectivamente. Esses autores atribuíram à topografia a principal fonte de variação da vegetação nesses ambientes, uma vez que as características físicas e químicas dos solos variam em função da posição topográfica da encosta. No presente estudo, a existência de fatores ambientais atuando sobre a distribuição da vegetação pode explicar a formação dos grupos florísticos, uma vez que se trata de um gradiente ambiental, cujas condições de solo e relevo variam ao longo da encosta e podem influenciar no estabelecimento das espécies arbóreas (GONÇALVES et al., 2011; PENÃ-CLAROS et al., 2012; SOUZA et al., 2012; DUBUIS et al., 2013; EISENLOHR et al., 2013; THUILLER, 2013; NARVAES et al., 2014).

No terço inferior da encosta verificamos que as espécies mais representativas são, em geral, higrófitas e preferem como o seu ótimo solos mais úmidos. Essa constatação está de acordo com os estudos de Veloso e Klein (1959) e Klein $(1980 ; 1984)$ realizados na mesma região. Esses autores apontaram que no terço inferior das encostas do Vale do Itajaí-SC a vegetação era caracterizada por espécies higrófitas, seguida das indiferentes. Nesse ambiente, as espécies higrófitas caracterizavam a vegetação pelo fato de apresentarem preferência por solos úmidos. Por exemplo, FerreiraJúnior et al. (2012) e Feng et al. (2013) apontaram que, de modo geral, o terço inferior das encostas é constituído por solos profundos e com maior reserva de água, pois são ambientes conservadores. Essas características pedogeomorfológicas do terço inferior da encosta provavelmente condicionam um ambiente preferencial para determinado conjunto de espécies.
Essa constatação foi verificada no presente estudo a partir da análise de espécies indicadoras, que indicou Actinostemon concolor, Alsophila setosa, Cyathea delgadii e Pterocarpus rohrii como espécies típicas do terço inferior da encosta.

O terço médio da encosta apresentou maior número de espécies indiferentes. Verificamos, ainda, que o número de espécies indicadoras foi menor quando comparado aos demais setores analisados, o que pode estar relacionado com a maior heterogeneidade ambiental proporcionada pelas condições edáficas e topográficas do terço médio da encosta (ver KLEIN, 1980; FERREIRA-JÚNIOR et al., 2012; SOUZA et al., 2012; 2013; NARVAES et al., 2014). O terço médio da encosta pode ser considerado como uma zona de transição entre a floresta do terço superior e a do terço inferior, motivo pelo qual registramos o maior número de espécies indiferentes. Klein (1980) verificou que na região do Vale do Itajaí-SC o terço médio das encostas era composto, predominantemente, por espécies dos outros setores (terços inferior e superior). Além disso, geralmente o terço médio possui características ambientais intermediárias quando comparado aos demais setores, as quais são favoráveis para o estabelecimento e desenvolvimento de várias espécies de plantas (GOMES et al., 2011). Portanto, em relação às adaptações ecológicas que as espécies possuem pelo teor de umidade do solo, as espécies indiferentes se sobressaem entre as xerófitas e higrófitas, o que certamente irá refletir no número de espécies indicadoras entre os setores, uma vez que as espécies indiferentes podem ocorrer em todos os setores por não apresentarem afinidades pelo teor de umidade do solo.

No terço superior da encosta, a predominância de espécies xerófitas sugere que esse setor pode ser um ambiente seletivo para algumas espécies. Klein (1980) aponta que o topo das encostas do Vale do Itajaí-SC era caracterizado por apresentar relevo acidentado, solos rasos e pobres em nutrientes, o que condicionava a vegetação a um porte reduzido devido às condições ambientais seletivas. Tratava-se de espécies adaptadas às condições ambientais extremas como, por exemplo, maior radiação solar incidindo no interior da floresta, menor umidade do solo e maior declividade do terreno, 
entre outros (KLEIN, 1980; 1984; FERREIRA-JÚNIOR et al., 2012; SCHAEFER et al., 2012; SOUZA et al., 2012; MARANGON et al., 2013). No terço superior da encosta, encontramos o maior número de espécies indicadoras quando comparado aos demais setores, evidenciando se tratar de um ambiente seletivo para algumas espécies (por exemplo, Myrcia pulchra e Podocarpus sellowii, entre outras). No presente estudo, fatores ambientais ligados à topografia do terreno e ao tipo de solo podem estar atuando sobre a vegetação do topo da encosta. Entretanto, estudos sobre a influência de fatores ambientais na vegetação devem ser realizados para confirmar essa hipótese.

Em relação à estrutura da floresta, o destaque de Euterpe edulis como espécie mais importante nos terços inferior e médio da encosta deve-se ao seu caráter de espécie indiferente, bem como aos seus elevados valores de densidade e frequência. Em áreas bem conservadas da Floresta Pluvial Subtropical de Santa Catarina, estudos recentes têm apontado Euterpe edulis como uma das espécies de maior densidade no interior das florestas (COLONETTI et al., 2009; SCHORN; GALVÃO, 2009; MAÇANEIRO et al., 2015b). Klein (1980) mencionou que as maiores densidades dessa espécie ocorriam em áreas com solos muito úmidos, onde podia ultrapassar os 1.000 ind.ha $^{-1}$. No entanto, o mesmo autor também verificou que Euterpe edulis ocorria com elevada densidade nas florestas de encosta, se tornando muitas vezes a espécie mais importante do estrato médio. No presente estudo, encontramos baixa importância estrutural de Euterpe edulis no terço superior da encosta, fato que pode estar relacionado com as características ambientais desse setor. Além disso, alguns estudos apontaram que Euterpe edulis prefere como o seu ótimo ambientes sombreados, com solos profundos e de elevada umidade (KLEIN, 1980; GATTI et al., 2011; BRANCALION et al., 2012). Assim, na área de estudo, o terço superior da encosta pode não apresentar as características ambientais favoráveis para o desenvolvimento dessa espécie.

Uma espécie que merece destaque foi Sloanea guianensis, que esteve presente entre as mais importantes de todas as posições da encosta. Essa espécie é considerada como uma das mais importantes da Floresta
Pluvial Subtropical de Santa Catarina, ocorrendo em todas as formações vegetacionais das encostas da Serra do Mar, motivo pelo qual é classificada como espécie indiferente, pois não apresenta preferência por determinado tipo de solo (SMITH JR; SMITH, 1970). Além disso, essa espécie já foi apontada como uma das dominantes do estrato superior das florestas do Vale do Itajaí-SC (KLEIN, 1980; 1984), e, com Ocotea catharinensis, caracterizava o dossel das florestas primárias estabelecidas em grande parte das encostas das serras dessa região (VELOSO; KLEIN 1957; 1959). Apesar da área de estudo ter sido alvo de exploração madeireira no início de 1900, constatamos que Ocotea catharinensis se destacou entre as espécies mais importantes do terço inferior da encosta. No entanto, seus valores estruturais foram muito aquém dos registrados por Veloso e Klein (1957) e Weber et al. (1992), em dois remanescentes de Floresta Pluvial Subtropical primária no Vale do Itajaí-SC, onde cerca de $20 \%$ da área basal da floresta era composta por essa espécie. Nas florestas primárias dessa região, Ocotea catharinensis era a única espécie dominante do estrato superior, representando entre $30-50 \%$ da cobertura superior (KLEIN, 1980). Essa espécie também apresentava indivíduos de porte agigantado e era responsável por um terço de todo o volume de madeira em 1 ha (REITZ et al., 1978). Atualmente, devido à exploração predatória que essa espécie sofreu, é possível encontrar apenas indivíduos jovens no interior das florestas e as áreas que ainda protegem certa porção das populações naturais dessa espécie estão localizadas principalmente em Unidades de Conservação, como é o caso da RPPN Chácara Edith.

Entre as espécies que amostramos nesse estudo, Cyathea delgadii e Alsophila setosa se destacaram como as mais importantes do terço inferior da encosta, principalmente pelos seus elevados valores de densidade. Além disso, essas espécies foram consideradas como indicadoras, evidenciando sua preferência por esse setor. $\mathrm{O}$ destaque dessas espécies provavelmente está relacionado com as preferências que elas possuem pelo tipo de solo, uma vez que são consideradas espécies higrófitas, preferindo como o seu ótimo ambientes com solos mais úmidos. Já para Cyathea corcovadensis, não verificamos valores estruturais expressivos no terço inferior da encosta, mas no terço médio essa espécie se 
destacou entre as mais importantes e foi considerada como espécie indicadora, demonstrando preferência por essa posição da encosta. O destaque de Cyathea delgadii e Alsophila setosa no terço inferior e Cyathea corcovadensis no terço médio pode estar relacionado com o estabelecimento preferencial que elas possuem no sub-bosque das florestas, uma vez que preferem ambientes mais sombreados e úmidos, onde podem ocorrer com muitos indivíduos (SEVEGNANI et al., 2013). Por outro lado, no terço superior da encosta não verificamos importância expressiva dessas espécies, o que pode ser explicado, em parte, pelas características ambientais proporcionadas pela posição topográfica do terreno, pois no terço superior as características edáficas e topográficas são muito diferenciadas quando comparadas aos demais setores (KLEIN, 1980; 1984; FERREIRA-JÚNIOR et al., 2012; SCHAEFER et al., 2012). Além disso, a elevada densidade encontrada para Alsophila setosa, Cyathea delgadii e Cyathea corcovadensis na área de estudo pode estar relacionada com o estado de conservação da floresta, pois no interior de florestas bem conservadas essas espécies podem formar densos agrupamentos (VELOSO; KLEIN, 1957; KLEIN, 1980; FERNANDES, 1997).

Ocotea aciphylla, Tapirira guianensis e Vantanea compacta se destacaram entre as mais importantes dos terços médio e superior da encosta. Entretanto, no terço inferior, essas espécies não apresentaram valores estruturais expressivos. Essa constatação pode estar relacionada, em parte, com as exigências ecológicas que essas espécies possuem na área de estudo, uma vez que são consideradas por Veloso e Klein (1959) e Klein (1980) como xerófitas, preferindo ambientes com solos mais secos. No entanto, Tapirira guianensis já foi apontada como a mais importante em florestas paludícolas (MARQUES et al., 2003; ROCHA et al., 2005; TEIXEIRA; ASSIS, 2009; MAGALHÃES; MAIMONI-RODELLA, 2012), indicando se tratar de espécie generalista em termos de condições ambientais, podendo ocorrer desde o terço superior das encostas, cujos solos são mais secos, até o terço inferior das encostas, caracterizados por baixadas e várzeas brejosas, cujos solos podem ser hidromórficos. Reitz (1967) menciona Vantanea compacta como espécie seletiva xerófita exclusiva das partes superiores das encostas do Vale do Itajaí, onde é muito abundante, tornando-se rara nas partes inferiores das encostas cujos solos são mais úmidos. Por outro lado, Ocotea acyphilla já foi apontada como muito importante em outras formações vegetacionais da Floresta Pluvial Subtropical de Santa Catarina, principalmente na Floresta Pluvial Subtropical de Baixada, cujos solos são arenosos e pobres em nutrientes (KLEIN, 1980; 1984; NEGRELLE, 2006). Além disso, essas espécies já foram registradas como dominantes e subdominantes das florestas primárias (KLEIN, 1980) e secundárias (MAÇANEIRO et al., 2015a) estabelecidas no alto das encostas do Vale do Itajaí, ocorrendo principalmente nas porções superiores das encostas (REITZ, 1967; KLEIN, 1984). No presente estudo, o destaque dessas espécies como as mais importantes nos terços médio e superior da encosta indica que a floresta se encontra em estágio muito avançado do processo de sucessão.

Nossos resultados indicaram que as variações na composição e estrutura de uma Floresta Pluvial Subtropical no Sul do Brasil permitem detectar agrupamentos florísticos. Além disso, verificamos um padrão estatisticamente significativo na formação dos grupos florísticos em função da posição da encosta. Cada grupo florístico foi caracterizado por um conjunto de espécies indicadoras, sendo que no terço inferior da encosta predominaram as espécies higrófitas; no terço médio, as espécies indiferentes e no terço superior, as espécies xerófitas. Os resultados permitem concluir que os grupos florísticos analisados se mostraram consistentes com as zonas vegetacionais descritas por Veloso e Klein $(1959)$ e Klein $(1980 ; 1984)$ para a Floresta Pluvial Subtropical da região do Vale do Itajaí, em Santa Catarina, e que seus estudos históricos apresentam validade estatística nos dias atuais.

\section{Agradecimentos}

À Coordenação de Aperfeiçoamento de Pessoal de Nível Superior (CAPES), pela concessão da bolsa de estudos do primeiro autor, e ao Programa de PósGraduação em Engenharia Florestal da Universidade Regional de Blumenau (FURB), pelo auxílio financeiro prestado para execução desta pesquisa. 


\section{Referências}

ALVARES, C.A.; STAPE, J.L.; SENTELHAS, P.C.; GONÇALVES, J. L. M.; SPAROVEK, G. Köppen's climate classification map for Brazil. Meteorologische Zeitschrift, Vienna, v. 22, n. 6, p. 711$728,2014$.

BRANCALION, P. H. S.; VIDAL, E.; LAVORENTI, N. A.; BATISTA, J. L. B.; RODRIGUES, R. R. Soil-mediated effects on potential Euterpe edulis (Arecaceae) fruit and palm heart sustainable management in the Brazilian Atlantic Forest. Forest Ecology and Management, Amsterdam, v. 284, n. 4, p. 78-85, 2012.

CLARKE, K. R. Non-parametric multivariate analysis of changes in community structure. Australian Journal of Ecology, Carlton, v. 18, n. 1, p. 117-143, 1993.

COLONETTI, S.; CITADINI-ZANETTE, V.; MARTINS, R.; SANTOS, R.; ROCHA, R.; JARENKOW, J. A. Florística e estrutura fitossociológica em Floresta Ombrófila Densa submontana na barragem do rio São Bento, Siderópolis, estado de Santa Catarina. Acta Scientiarum. Biological Sciences, Maringá, v. 31, n. 4, p. $397-405,2009$.

DUBUIS, A.; GIOVANETTINA, S.; PELLISSIER, L.; POTTIER, J.; VITTOZ, P.; GUISAN, A. Improving the prediction of plant species distribution and community composition by adding edaphic to topo-climatic variables. Journal of Vegetation Science, Xalapa, v. 24, n. 4, p. 593-606, 2013.

EISENLOHR, P. V.; ALVES, L. F.; BERNACCI, L. C.; PADGURSCHI, M. C. G.; TORRES, R. B.; PRATA, E. M. B.; SANTOS, F. A. M.; ASSIS, M. A.; RAMOS, E.; ROCHELLE, A. L. C.; MARTINS, F. R.; CAMPOS, M. C. R.; PEDRONI, F.; SANCHEZ, M.; PEREIRA, L. S.; VIEIRA, S. A.; GOMES, J. A. M. A.; TAMASHIRO, J. Y.; SCARANELLO, M. A. S.; CARON, C. J.; JOLY, A. C. Disturbances, elevation, topography and spatial proximity drive vegetation patterns along an altitudinal gradient of a top biodiversity hotspot. Biodiversity and Conservation, New York, v. 22, n. 12, p. 2767-2783, 2013.

EMBRAPA - EMPRESA BRASILEIRA DE PESQUISA AGROPECUÁRIA. Solos do estado de Santa Catarina. Rio de Janeiro: Embrapa Solos, 2004. 745 p.

FENG, Q.; ZHAO, W.; QIU, Y.; ZHAO, M.; ZHONG, L. Spatial heterogeneity of soil moisture and the scale variability of its influencing factors: a case study in the Loess Plateau of China. Water, Basel, v. 5, n. 3, p. 1226-1242, 2013.

FERNANDES, I. Taxonomia e fitogeografia de Cyatheaceae e Dicksoniaceae nas regiões sul e sudeste do Brasil. 1997. $435 \mathrm{f}$. Tese (Doutorado em Ciências) - Universidade de São Paulo, São Paulo. 1997.

FERREIRA-JÚNIOR, W. G.; SCHAEFER, C. E. G. R.; SILVA, A. F. S. Uma visão pedogeomorfológica sobre as formações florestais da Mata Atlântica. In: MARTINS, S. V. (Ed.). Ecologia de florestas tropicais do Brasil. Viçosa: Editora UFV, 2012, p. 141-174.

FLORA DIGITAL. Plantas dos estados do Rio Grande do Sul e de Santa Catarina. 2016. Disponível em: $<\mathrm{http}$ :/www.ufrgs.br/ fitoecologia/florars/>. Acesso em: 4 fev. 2016.

GATTI, M. G.; CAMPANELLO, P.; GOLDSTEIN, G. Growth and leaf production in the tropical palm Euterpe edulis: light conditions versus developmental constraints. Flora, Jena, v. 206, n. 8, p. 742748,2011
GENTRY, A. H. Changes in plant community diversity and floristic composition on environmental and geographical gradients. Annals of the Missouri Botanical Garden, St. Louis, v. 75, n. 1, p. 1-34, 1988 .

GOMES, J. A. M. A.; BERNACCI, L. C.; JOLY, C. A. Diferenças florísticas e estruturais entre duas cotas altitudinais da Floresta Ombrófila Densa Submontana Atlântica, do Parque Estadual da Serra do Mar, município de Ubatuba/SP, Brasil. Biota Neotropica, Campinas, v. 11, n. 2, p. 123-137, 2011.

GONÇALVES, I. S.; DIAS, H. C. T.; MARTINS, S. V.; SOUZA, A. L. Fatores edáficos e as variações florísticas de um trecho de mata ciliar do Rio Gualaxo do Norte, Mariana, MG. Revista Árvore, Viçosa, v. 35, n. 6, p. 1235-1243, 2011.

HAIR, J. F.; ANDERSON, R. E.; TATHAM, R. L.; BLACK, W. C. Análise multivariada de dados. Porto Alegre: Bookman, 2009. $688 \mathrm{p}$.

KLEIN, R. M. Ecologia da flora e vegetação do Vale do Itajaí. Sellowia, Itajaí, v. 1, n. 31, p. 1-164, 1979.

KLEIN, R. M. Ecologia da flora e vegetação do Vale do Itajaí. Sellowia, Itajaí, v. 1, n. 33, p. 165-389, 1980.

KLEIN, R. M. Aspectos dinâmicos da vegetação do sul do Brasil. Sellowia, Itajaí, v. 1, n. 36, p. 5-54, 1984.

MAÇANEIRO, J. P.; OLIVEIRA, L. Z.; SEUBERT, R. C.; EISENLOHR, P. V.; SCHORN, L. A. More than environmental control at local scales: do spatial processes play an important role on floristic variations in Subtropical Forests?. Acta Botanica Brasilica, Feira de Santana, v. 30, n. 2, p. 183-192, 2016.

MAÇANEIRO, J. P.; SCHORN, L. A.; SEVEGNANI, L.; VIBRANS, A. C. Structure of the tree component and indicator species in different types of forests in the Itajaí-Mirim river, Southern Brazil. Australian Journal of Basic and Applied Sciences, Jordan, v. 9, n. 33, p. 392-397, 2015a.

MAÇANEIRO, J. P.; SEUBERT, R. C.; SCHORN, L. A. Fitossociologia de uma Floresta Pluvial Subtropical Primária no Sul do Brasil. Floresta, Curitiba, v. 45, n. 3, p. 555-566, 2015 b.

MAGALHÃES, J. H. R.; MAIMONI-RODELLA, R. C. S. Floristic composition of a freshwater swamp forest remnant in southeastern Brazil. Check List, France, v. 8, n. 4, p. 832-838, 2012.

MARANGON, L. C.; SOARES, J. J.; FELICIANO, A. L. P.; LANI, J. L.; MATOS, L. V. Relação entre vegetação e pedoformas na Mata do Paraíso, município de Viçosa, Minas Gerais. Revista Árvore, Viçosa, v. 37, n. 3, p. 441-450, 2013

MARQUES, M. C. M.; SILVA, S. M.; SALINO, A. Florística e estrutura do componente arbustivo-arbóreo de uma floresta higrófila da bacia do rio Jacaré-Pepira, SP, Brasil. Acta Botanica Brasilica, Feira de Santana, v. 17, n. 4, p. 495-506, 2003.

McCUNE, B.; GRACE, J. B. Analysis of ecological communities. Gleneden Beach: MjM, 2002. 304 p.

McCUNE, B.; MEFFORD, M. J. PC-ORD. Multivariate analysis of ecological data, Version 6. Gleneden Beach: MjM Software Design, 2011. Disponível em: < https:/www.pcord.com/pc6fixes. $\mathrm{htm}>$.

MENDES, C. A. R.; MAHLER, C. F.; ANDRADE, A. G. Erosão superficial em argissolo amarelo sob cultivo perene e com pousio florestal em área de relevo montanhoso. Revista Brasileira de Ciência do Solo, Viçosa, v. 35, n. 4, p. 1387-1396, 2011. 
MOESLUND, J. E.; ARGE, L.; BØCHER, P. K.; DALGAARD, T.; SVENNING, J. C. Topography as a driver of local terrestrial vascular plant diversity patterns. Nordic Journal of Botany, Lund, v. 31, n. 2, p. 129-144, 2013.

MUELLER-DOMBOIS, D.; ELLENBERG, H. Aims and methods of vegetation ecology. New Jersey: The Blackburn Press, 2002. $547 \mathrm{p}$.

NARVAES, I. S.; LONGHI, S. J.; KILCA, R. V.; RODRIGUES, T. E. S. Arboreous species population in a topographic gradient of Mixed Ombrophilous Forest in Rio Grande do Sul. Floresta, Curitiba, v. 44, n. 4, p. 553-564, 2014.

NEGRELLE, R. R. B. Composição florística e estrutura vertical de um trecho de Floresta Ombrófila Densa de Planície Quaternária. Hoehnea, São Paulo, v. 33, n. 3, p. 261-289, 2006.

OLIVEIRA-FILHO, A. T. Um sistema de classificação fisionômicoecológico da vegetação neotropical: segunda aproximação. In: EISENLOHR, P. V.; FELFILI, J. M.; MELO, M. M. R. F.; ANDRADE, L. A.; MEIRA NETO, J. A. A. (Ed.). Fitossociologia no Brasil: métodos e estudos de casos. Viçosa: Editora UFV, 2015. p. $452-473$.

PANDOLFO, C.; BRAGA, H. J.; SILVA JÚNIOR, V. P.; MASSIGNAN, A. M.; PEREIRA, E. S.; THOMÉ, V. M. R.; VALCI, F. V. Atlas climatológico do estado de Santa Catarina Florianópolis: Epagri, 2002. CD-ROM.

PENÃ-CLAROS, M.; POORTER, L.; ALARCÓN, A.; BLATE, G.; CHOQUE, U.; FREDERICKSEN, T. S.; JUSTINIANO, M. J.; LEAÑO, C.; LICONA, J. C.; PARIONA, W.; PUTZ, F. E.; QUEVEDO, L.; TOLEDO, M. Soil effects on forest structure and diversity in a moist and a dry Tropical Forest. Biotropica, Malden, v. 44, n. 3, p. 276-283, 2012.

PHILIPP, R. P.; MALLMANN, G.; BITERCOURT, M. F.; SOUZA, E. R.; SOUZA, M. M. A.; LIZ, J. D.; WILD, F.; ARENDT, S.; OLIVEIRA, A. S.; DUARTE, L.; RIVEIRA, C. B.; PRADO, M. Caracterização litológica e evolução metamórfica da porção leste do Complexo Metamórfico Brusque, Santa Catarina. Revista Brasileira de Geociências, Curitiba, v. 34, n. 1, p. 21-34, 2004.

PITMAN, N. C. A.; TERBORGH, J. W.; SILMAN, M. R.; VARGAS, P. N.; NEILL, D. A.; CERÓN, C. E.; PALACIOS, W. A.; AULESTIA, M. A comparison of tree species diversity in two upper Amazonian forests. Ecology, New York, v. 83, n. 11, p. 32103224, 2002.

POULSEN, A. D.; TUOMISTO, H.; BALSLEV, H. Edaphic and floristic variation within a 1-ha plot of Lowland Amazonian Rain Forest. Biotropica, Malden, v. 38, n. 4, p. 468-478, 2006.

REFLORA. Herbário Virtual. 2016. Disponível em: <http:// reflora.jbrj.gov.br/jabot/herbarioVirtual/>. Acesso em: 4 fev. 2016.

REITZ, R. Humiriáceas. In: REITZ, R. (Ed.). Flora ilustrada catarinense. Itajaí: Herbário Barbosa Rodrigues, 1967. 10 p.

REITZ, R.; KLEIN, R. M.; REIS, A. Projeto madeira de Santa Catarina. Sellowia, Itajaí, v. 1, n. 28, p. 11-320, 1978.

RESENDE, M. Pedologia e fertilidade do solo: interações e aplicações. Brasília: MEC/ESAL/POTAFOS, 1988. 81 p.

ROCHA, C. T. V.; CARVALHO, D. A.; FONTES, M. A. L.; OLIVEIRA-FILHO, A. T.; VAN DEN BERG, E.; MARQUES, J. J. G. S. M. Comunidade arbórea de um continuum entre floresta paludosa e de encosta em Coqueiral, Minas Gerais, Brasil. Revista Brasileira de Botânica, São Paulo, v. 28, n. 2, p. 203-218, 2005.
RODRIGUES, L. A.; CARVALHO, D. A.; OLIVEIRA-FILHO, A. T.; CURI, N. Efeitos de solos e topografia sobre a distribuição de espécies arbóreas em um fragmento de floresta estacional semidecidual, em Luminárias, MG. Revista Árvore, Viçosa, v. 31, p. 25-35, 2007.

SANTA CATARINA. Atlas de Santa Catarina. Gabinete de Planejamento e Coordenação Geral. Florianópolis: GAPLAN/ SUEGI, 1986. 173 p.

SCHAEFER, C. E. G. R.; MENDONÇA, B. A. F.; FERREIRAJÚNIOR, W. G.; VALENTE, E.; CORREA, G. R. Relações solo-vegetação em alguns ambientes brasileiros: fatores edáficos e florística. In: MARTINS, S. V. (Ed.). Ecologia de florestas tropicais do Brasil. Viçosa, Editora UFV, 2012. p. 252-293.

SCHAEFER, C. E. G. R.; NUNES, J. A.; NERI, A. V.; MENDONÇA, B. A. F.; FERREIRA-JÚNIOR, W. G.; ARRUDA, D. M.; TEIXEIRA, R. D. B. L. Relação solo-vegetação em formações vegetacionais brasileiras: metodologia e estudos de caso. In: EISENLOHR, P. V.; FELFILI, J. M.; MELO, M. M. R. F.; ANDRADE, L. A.; MEIRA NETO, J. A. A. (Ed.). Fitossociologia no Brasil: métodos e estudos de casos. Viçosa: Editora UFV, 2015. p. 322-343.

SCHORN, L. A.; GALVÃO, F. Dinâmica do estrato arbóreo em três estádios sucessionais de uma Floresta Ombrófila Densa em Blumenau, SC. Cerne, Lavras, v. 15, n. 2, p. 221-235, 2009.

SCHULZ-JÚNIOR, A.; ALBUQUERQUE, L. F. F. Geologia da quadrícula Rio do Sul, Santa Catarina. Porto Alegre: DNPM, 1969. $272 \mathrm{p}$.

SENTHILKUMAR, S.; KRAVCHENKO, A. N.; ROBERTSON, G. P. Topography influences management system effects on total soil carbon and nitrogen. Soil Science Society of America Journal, Madison, v. 73, n. 6, p. 2059-2067, 2009.

SEVEGNANI, L.; UHLMANN, A.; GASPER, A. L.; VIBRANS, A. C.; SANTOS, A. S.; VERDI, M.; DREVECK, S.; KORTE, A.; MEYER, L. Estádios sucessionais na Floresta Ombrófila Densa em Santa Catarina. In: VIBRANS, A. C.; SEVEGNANI, L.; GASPER, A. L.; LINGNER, D. V. (Ed.). Inventário florístico florestal de Santa Catarina: Floresta Ombrófila Densa. Blumenau: Edifurb, 2013. p. 311-322.

SMITH JR, C. E.; SMITH, L. B. Eleocarpáceas. In: REITZ, R. (Ed.). Flora ilustrada catarinense. itajaí: Herbário Barbosa Rodrigues, 1970. 33 p.

SOARES, C. P. B.; PAULANETO, F.; SOUZA, A. L. Dendrometria e inventário florestal. Viçosa: Editora UFV, 2012. 272 p.

SOUZA, P. B.; LELIS, J. J.; SCHAEFER, C. E. G. R.; SOUZA, A. L.; MEIRA NETO, J. A. A. Distribution of tree species in a geomorphological and pedological gradient of submontane Semidecidual Seasonal Forest in the Vicinity of Rio Doce State Park, Minas Gerais. Revista Árvore, Viçosa, v. 36, n. 4, p. $707-$ 718, 2012.

SOUZA, P. B.; MEIRA NETO, J. A. A.; SOUZA, A. L. Diversidade florística e estrutura fitossociológica de um gradiente topográfico em Floresta Estacional Semidecidual Submontana, MG. Cerne, Lavras, v. 19, n. 3, p. 489-499, 2013.

TEIXEIRA, A. P.; ASSIS, M. A. Relação entre heterogeneidade ambiental e distribuição de espécies em uma floresta paludosa no Município de Cristais Paulista, SP, Brasil. Acta Botanica Brasilica, Feira de Santana, v. 23, n. 3, p. 843-853, 2009. 
ter STEEGE, H.; PITMAN, N.; SABATIER, D.; CASTELLANOS, H.; HOUT, P. V. D.; DALY, D. C.; SILVEIRA, M.; PHILLIPS, O.; VASQUEZ, R.; ANDEL, T. V.; DUIVENVOORDEN, J.; OLIVEIRA, A. A.; EK, R.; LILWAH, R.; THOMAS, R.; ESSEN, J. V.; BAIDER, C.; MAAS, P.; MORI, S.; TERBORGH, J.; VARGAS, P. N.; MOGOLLÓN, H.; MORAWETZ, W. A spatial model of treeadiversity and tree density for the Amazon. Biodiversity and Conservation, New York, v. 12, n. 11, p. 2255-2277, 2003.

ter STEEGE, H.; PITMAN, O. L.; PHILlIPS, J.; CHAVE, D.; SABATIER, A.; DUQUE, J. F.; MOLINO, M. F.; PREVOST, R.; SPICHIGER, H.; CASTELLANOS, P.; VON HILDEBRAND; VASQUEZ, R. Continental-scale patterns of canopy tree composition and function across Amazonia. Nature, London, v. 443, p. 444-447, 2006.

THUILLER, W. On the importance of edaphic variables to predict plant species distributions - limits and prospects. Journal of Vegetation Science, Xalapa, v. 24, n. 4, p. 591-592, 2013.
TICHÝ. L.; CHYTRÝ, M. Statistical determination of diagnostic species for site groups of unequal size. Journal of Vegetation Science, Xalapa, v. 17, n. 6, p. 809-818, 2006.

VELOSO, H. P.; KLEIN, R. M. As comunidades do município de Brusque, estado de Santa Catarina. Sellowia, Itajaí, v. 1, n. 8, p. 81-235, 1957.

VELOSO, H. P.; KLEIN, R. M. Dinamismo e fidelidade das espécies em associações do município de Brusque, estado de Santa Catarina. Sellowia, Itajaí, v. 1, n. 10, p. 9-124, 1959.

WEBER, O. L.; STEINBACH, F.; LONGO, A. N.; MERIZIO, D. Levantamento da estrutura da Mata Atlântica de encosta na Fazenda Faxinal para fins de manejo natural. Revista do Instituto Florestal, São Paulo, v. 4, n. 1, p. 330-331, 1992. 